\title{
Preoperative Evaluation of Tractional Retinal Detachment with B-Mode Ultrasonography in Diabetic Vitreous Hemorrhage
}

\author{
Dokhan Demir, ${ }^{1}$ (i) Murat Arici, ${ }^{2}$ (ㄱ) Zeynep Alkin ${ }^{3}$
}

${ }^{1}$ Department of Ophthalmology, University of Health Sciences, Fatih Sultan Mehmet Training and Research Hospital, Istanbul, Turkey 2Department of Ophthalmology, Tunceli Public Hospital, Tunceli, Turkey

${ }^{3}$ Department of Ophthalmology, Etiler World Eye Hospital, Istanbul, Turkey

\begin{abstract}
Objectives: This study was designed to evaluate the reliability of preoperative ultrasonography (USG) to detect tractional retinal detachment (TRD) in vitreous hemorrhage $(\mathrm{VH})$ due to proliferative diabetic retinopathy.

Methods: The medical records of patients with $\mathrm{VH}$ who underwent $\mathrm{A}$ - and B-scan ultrasonography prior to a vitrectomy between November 2016 and May 2017 were reviewed in this retrospective study. All of the patients were assessed using USG before surgery with 4-quadrant transverse and I-quadrant longitudinal scans whether to determine if the $\mathrm{VH}$ was accompanied by TRD. The USG results were compared with the vitrectomy findings.

Results: A total of III eyes of 106 patients with VH were evaluated. Twenty-three eyes were excluded from the study due to non-diabetic diagnoses, such as retinal vein-artery occlusion, trauma, intraocular mass, choroidal neovascular membrane, or macroaneurysm. The remaining 88 eyes with diabetic $\mathrm{VH}$ were included in the study. Preoperatively, $\mathrm{VH}$ alone was observed in 65 eyes (73.8\%) and VH accompanied with TRD was determined in 23 eyes (26.2\%) using USG. TRD was not found during the operation in 2 eyes (2.2\%) diagnosed as VH with TRD by USG (false positive), and in 8 eyes (9.1\%), TRD was detected during surgery though VH alone had been recorded based on the USG results (false negative). Conclusion: USG is a reliable diagnostic tool that will provides accurate preoperative information about the presence of TRD in diabetic VH; however, in some cases TRD may go undetected, especially in eyes with peripherally localized or small TRD.
\end{abstract}

Keywords: Hemorrhage, tractional retinal detachment, ultrasonography

\section{Introduction}

Proliferative diabetic retinopathy (PDR) is an important cause of blindness in the young and middle-aged population (I). PDR manifests with retinal ischemia and neovascularization, which can result in vitreous hemorrhage $(\mathrm{VH})$ and tractional retinal detachment (TRD). Posterior vitreous detachment (PVD), with or without retinal tear or retinal detachment and ocular trauma, are the most common causes of $\mathrm{VH}(2-6)$. PDR is the most frequent cause of spontaneous $\mathrm{VH}$, which can be dense enough to prevent visualization of

How to cite this article: Demir G, Arici M, Alkin Z. Preoperative Evaluation of Tractional Retinal Detachment with B-Mode Ultrasonography in Diabetic Vitreous Hemorrhage. Beyoglu Eye J 202I; 6(I): 49-53.

Address for correspondence: Gokhan Demir, MD. Saglik Bilimleri Universitesi, Fatih Sultan Mehmet Egitim ve Arastirma Hastanesi, Istanbul, Turkey

Phone: +90 5425510246 E-mail: dr.gkhndmr@gmail.com

Submitted Date: October 05, 2020 Accepted Date: January 12, 2021 Available Online Date: February 10, 2021

${ }^{\circ}$ Copyright 2021 by Beyoglu Eye Training and Research Hospital - Available online at www.beyoglueye.com OPEN ACCESS This work is licensed under a Creative Commons Attribution-NonCommercial 4.0 International License. 
fundus details (7). The presumed mechanism of $\mathrm{VH}$ is bleeding from neovascular vessels caused by the tractional effect of acute PVD (4). Sometimes bleeding can occur even in the absence of proliferative disease.

Ultrasonography (USG) uses piezoelectric lead-zirconate-titanate crystals that generate an electronic charge, which creates an ultrasonic (inaudible, $>20 \mathrm{kHz}$ ) sound wave. The sound wave is reflected back from any echodense object. The piezoelectric crystals pick up the reflected sound and convert it to electric signals, which provide the echogram image. USG is very valuable in ophthalmology, as in other fields (8). Ocular USG is a very useful tool in the evaluation of the posterior ocular fundus, particularly when fundus details are obscured by blood or any other media opacity. USG can provide information regarding the morphology of the vitreous and the retina, as well as the localization and extent of any hemorrhage $(9,10)$. USG can deliver a highly accurate diagnosis of posterior eye segment pathology (II). Yet, in spite of recent advances in ophthalmological examination techniques, preoperative evaluation of vitreoretinal diseases accompanied by $\mathrm{VH}$ are often difficult to diagnose. USG offers an opportunity to plan surgery and follow-up when surgery is not the first-line therapy. The objective of this study was to assess the detection of TRD with USG in patients with $\mathrm{VH}$ caused by diabetic retinopathy.

\section{Methods}

This retrospective study included patients with $\mathrm{VH}$ who underwent B-scan USG prior to a vitrectomy at Beyoglu Eye Training and Research Hospital between November 2016 and May 2017. All of the patients had dense VH that prevented visualization of the fundus. The study procedure adhered to the Declaration of Helsinki. Institutional ethics committee approval was obtained to collect patient data.

The records of III eyes of 106 patients with $\mathrm{VH}$ were reviewed. Twenty-three eyes $(20.7 \%)$ with $\mathrm{VH}$ were excluded due to non-diabetic $\mathrm{VH}$, such as retinal vein occlusion ( 12 eyes), trauma ( 6 eyes), intraocular mass (I eye), hemorrhagic choroidal neovascular membrane (I eye), retinal artery occlusion (I eye), or suprachoroidal hemorrhage (I eye). The remaining 88 eyes were determined to have diabetic $\mathrm{VH}$, with or without TRD. Before undergoing a vitrectomy, all of the patients were evaluated with USG. In a seated position, the A- and B-scan USG procedures were initiated by administering topical propacaine hydrochloride drops. Subsequently, carbomer gel was applied on the eyelids for the B-scan to improve sound penetration of the eye. A linear transducer was placed on the eyelid and pressed smoothly on the eyeball. Axial horizontal, axial vertical, and vertical transverse scans are used to detect TRD. The vitreous cavity was evaluated in terms of bleeding intensity and mobility, and other pathologies. Retinal elevation and traction were recorded by carefully scanning the globe in all 4 quadrants. To study the vitreoretinal relationships more accurately, dynamic B-scanning was used on each eye during ocular movements. TRD was defined as a tent-like and/or table-top configuration observed on the B-scan and a retinal peak on the A-scan. Tent-like TRD is produced by pointed echoes, while table-top detachment is the result of broader vitreoretinal adherence (Fig. I).

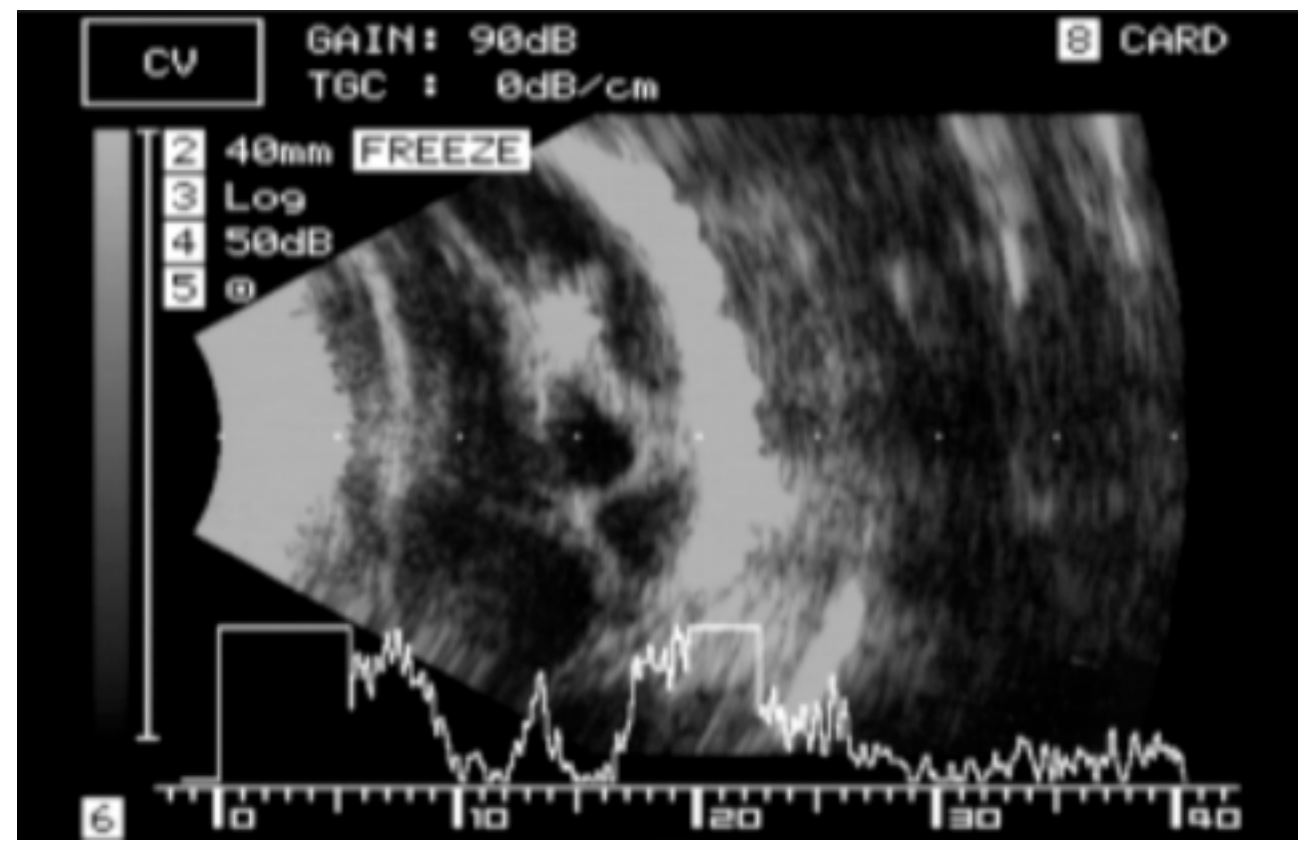

Figure I. B- and A-scan showing tractional retinal detachment. 
All of the USG procedures were performed with the EZ scan 5500 (Sonomed Escalon Inc., Wayne, PA, USA) using a $10-\mathrm{mHz}$ probe. The A-scan was used at the tissue sensitivity gain setting to assess the reflectivity of the suspected pathology. The USG findings were photographed. The USG examination was performed by an experienced vitreo-retinal surgeon in all cases. The surgical procedure was a three-port pars plana vitrectomy with endolaser photocoagulation of the ischemic retinal areas using the Constellation system (Alcon Laboratories, Inc., Fort Worth, TX, USA). When TRD was present in addition to the $\mathrm{VH}$, all of the tractional membranes were peeled off and an intraocular tamponade (silicone oil or gas [SF6/C3F8]) was injected. The intraoperative findings were compared with those of the preoperative A- and B-scans. A false-positive was defined as positive USG results in the absence of surgical findings, and a false-negative was defined as a negative USG result with a positive surgical finding. The specificity and sensitivity were calculated using the formula described by Dickie et al. (I2).

\section{Results}

The study population included 88 eyes of 83 patients with diabetic $\mathrm{VH}: 32$ women and $5 \mathrm{I}$ men. Bilateral involvement was observed in 5 patients. The mean age of the participants was $60.95 \pm \mathrm{II} .4$ years.

USG examination revealed preoperative $\mathrm{VH}$ in 65 eyes (73.8\%) and $\mathrm{VH}$ plus TRD in 23 eyes (26.2\%). Among the 65 eyes with VH, TRD was detected in 8 eyes (12.3\%) during vitrectomy when it had not been observed during the USG examination. The TRD was peripherally located in 3 eyes and very small in 5 eyes, which explains why it was not detected with USG. The VH diagnosis was confirmed during the vitrectomy in the remaining 57 eyes (87.7\%). TRD was not observed during the procedure in 2 of 23 eyes (8.6\%) that were found to have TRD in the USG examination. In these 2 eyes, very intense hemorrhaging at the posterior retinal wall was mistaken for TRD. The presence of TRD plus $\mathrm{VH}$ was confirmed during surgery in $2 \mathrm{l}$ eyes (9l.4\%) eyes assessed as such with the preoperative USG examination. Table I illustrates the distribution of $\mathrm{VH}$ and TRD as detected by USG or surgery.

The sensitivity and specificity of B-scan USG for the recognition of TRD in diabetic VH was $72.4 \%$ and $96.6 \%$, respectively.

\section{Discussion}

USG is a very useful technique to evaluate eyes with diabetic retinopathy and $\mathrm{VH}$, especially when visualization of the fundus is not possible. USG can provide information useful to the diagnosis, prognosis, and plans for treatment of diabetic retinopathy and other ocular diseases $(9,10)$. In this study, PDR (79.3\%) was the most common cause of $\mathrm{VH}$. In contrast, Lean and Gregor (4) and Lindgren et al. (5) reported vitreous detachment and traction of a retinal vessel (4I\%) as the most common cause of $\mathrm{VH}$. This difference is likely due to the fact that as a tertiary eye center, a large number of patients with advanced diabetic disease present at our institution.

The role of USG in determining TRD in eyes with blurry media has been clearly demonstrated in the past (I3). Currently, there is no other method for reliably detecting the anatomical position of the retina when direct examination is impossible. In the present study, USG accurately defined the anatomical conditions of the retina in 78 of 88 eyes (88.7\%), with 2 false positives (2.2\%) and 8 false negatives (9.1\%). The results reflect high specificity and positive predictive value, and somewhat lower sensitivity and negative predictive value. These data are consistent with those of Jack et al. (14), Jalkh et al. (15), and Kumar et al. (16), who found that preoperative USG had accurately determined the anatomical state of the retina in $84 \%$ to $89 \%$ of eyes with $\mathrm{VH}$. In more recent studies analyzing vitreoretinal diseases, the reported overall sensitivity of USG performed by ophthalmologists to assess

Table I. Distribution of patients with VH or VH plus TRD diagnosed by USG or during surgery

\begin{tabular}{lccc} 
Ultrasonography & VH & $\begin{array}{c}\text { Surgery (true status) } \\
\text { VH plus TRD }\end{array}$ & Total \\
\hline VH & 57 & 8 & 65 \\
VH plus TRD & True negative & False negative & 23 \\
& 2 & 21 & 88
\end{tabular}

TRD:Tractional retinal detachment; VH:Vitreous hemorrhage. 
the anatomical conditions of the retina has been $97.3 \%$ to $97.7 \%(16,17)$. In patients with more complex findings, such as choroidal detachment and TRD, a slightly lower agreement between USG and surgical findings of at $92 \%$ (19) and $92.2 \%$ (18) has been reported.

Inconsistency between USG and clinical findings is primarily due to the dynamic nature of the surgical procedure, the high degree of reflectance in cases of posterior vitreous detachment, and the complex echoes in eyes with PDR and TRD (17-19).

Parchand et al. (18) reported that the overall sensitivity and specificity of USG examination for the presence of TRD was $87.5 \%$ and $100 \%$, respectively. In our study, the sensitivity and specificity of B-scan USG for TRD in diabetic VH was $72.4 \%$ and $96.6 \%$, respectively. We think that the small number of patients in the previous study contributed to the higher rate. Significant changes, such as retinal detachment, can be reliably diagnosed with USG, even with limited resources. However, changes that can affect the management plan and the final prognosis require more detailed examination by an experienced ophthalmologist.

Our study was performed with a $10-\mathrm{MHz}$ probe. Hewick et al. (2I) compared a $10-\mathrm{MHz}$ probe with $20-\mathrm{MHz}$ probe and found that the $20-\mathrm{MHz}$ probe offered greater resolution of the chorioretina, sclera, optic nerve sheaths, retinal disorders, and extraocular muscles. The lower USG sensitivity (72.4\%) seen in our study compared with some other research is due to the fact that some instances of TRD were missed $(17,19,20)$. This may have occurred because the TRD was very small or peripherally located, or as a consequence of the probe's lower resolution $(10 \mathrm{mHz})$.

The principal limitation of this study is the relatively small number of patients compared with other studies in the literature $(15,20,22)$. For conclusive results, future studies with a larger number of patients are required.

Preoperative USG is a reliable diagnostic tool that provides largely accurate information with respect to the presence of TRD in diabetic VH. Some peripherally located or small TRD may not be recognized in a USG examination.

\section{Disclosures}

Ethics Committee Approval: The Medical Specialty Education Board in Beyoglu Eye Training and Research Hospital 19/C-3 $31 / 10 / 2018$

Peer-review: Externally peer-reviewed.

Conflict of Interest: None declared.

Authorship Contributions: Involved in design and conduct of the study (ZTA); preparation and review of the study (GD, MA); data collection (MA); and statistical analysis (GD).

\section{References}

I. Klein BE. Overview of epidemiologic studies of diabetic retinopathy. Ophthalmic Epidemiol 2007;14:179-83. [CrossRef]

2. Butner RW, McPherson AR. Spontaneous vitreous hemorrhage. Ann Ophthalmol 1982;14:268-70.

3. Dana MR, Werner MS, Viana MA, Shapiro MJ. Spontaneous and traumatic vitreous hemorrhage. Ophthalmology 1993; 100: 1377-83. [CrossRef]

4. Lean JS, Gregor Z. The acute vitreous hemorrhage. Br J Ophthalmol 1980;64:469-7I. [CrossRef]

5. Lindgren G, Sjodell L, Lindblom B. A prospective study of dense spontaneous vitreous hemorrhage. Am J Ophthalmol 1995; I 19:458-65. [CrossRef]

6. Spraul CW, Grossniklaus HE. Vitreous hemorrhage. Surv Ophthalmol I997;42:3-39. [CrossRef]

7. McMeel JW. Closed vitrectomy in diabetic retinopathy. In: Freeman HM, Hirose T, Schepens CL, editors. Vitreous surgery and advances in fundus diagnosis and treatment. New York: Appleton Century Crofts; 1977. p. 305-13.

8. Mundt GH, Hughes WF. Ultrasonics in ocular diagnosis. Am J Ophthalmol 1956;41:488-98. [CrossRef]

9. Mcleod D, Restori M. Ultrasonic examination in severe diabeticeye disease. Br J Ophthalmol 1979;63:533-8. [CrossRef]

10. Colemann DJ, Franzen LA. Vitreous surgery: preoperativeevaluation and prognostic value of ultrasonic display of vitreous haemorrhage. Arch Ophthalmol 1974;92:375-8I. [CrossRef]

II. Scott IU, Smiddy WE, Feuer WJ, Ehlies FJ. The impact of echography on evaluation and management of posterior segment disorders. Am J Ophthalmol 2004;137:24-9. [CrossRef]

12. Dickie GL. Statistical notes. Defining sensitivity and specificity. BMJ 1994;309:539. [CrossRef]

13. Blumenkranz MS, Byrne SF. Standardized echography (ultrasonography) for the detection and characterization of retinal detachment. Ophthalmology 1982;89:82 I-31. [CrossRef]

14. Jack RL, Hutton WL, Machemer R. Ultrasonography and vitrectomy. Am J Ophthalmol 1974;78:265-74. [CrossRef]

15. Jalkh AE, Avila MP, El-Markabi H, Trempe CL, Schepens CL. Immersion A- and B-scan ultrasonography. Arch Ophthalmol 1984; 102:686-90. [CrossRef]

16. Kumar A, Verma L, Jha SN, Tewari HG, Khosla PK. Ultrasonic errors in analysis of vitreous haemorrhage. Indian J Ophthalmol 1990;38:162-3.

17. Zvornicanin J, Jusufovic V, Cabric E, Musanovic Z. Significance of ultrasonography in evaluation of vitreo-retinal pathologies. Med Arch 2012;66:318-20. [CrossRef]

18. Parchand S, Singh R, Bhalekar S. Reliability of Ocular Ultrasonography findings for pre-surgical evaluation in various vit- 
reo-reti nal disorders. Semin Ophthalmol 2014;29:236-4I.

19. Rabinowitz R, Yagev R, Shoham A, Lifshitz T. Comparison between clinical and ultrasound findings in patients with vitreous hemorrhage. Eye (Lond) 2004; 18:253-6. [CrossRef]

20. Vrablik ME, Snead GR, Minnigan HJ, Kirschner JM, Emmett TW, Seupaul RA. The diagnostic accuracy of bedside ocular ultrasonography for the diagnosis of retinal detachment: a systematic review and meta-analysis. Ann Emerg Med 2015;65:199-203.el.

21. Hewick SA, Fairhead AC, Culy JC. A comparison of $10 \mathrm{MHz}$ and $20 \mathrm{MHz}$ ultrasound probes in imaging the eye and orbit. $\mathrm{Br}$ J Ophthalmol 2004;88:55 I-5. [CrossRef]

22. Capeans C, Santos L, Tourino R, Otero JL, Ulla FG, Salorio MS. Ocular echography in the prognosis of vitreous haemorrhage in type II diabetes mellitus. Int Ophthalmol 1997;2 1:269-75. 